Programa de Pós-Graduação em Engenharia de Produção - PPGEP

Laboratório de Qualidade de Vida - LaQVida

Universidade Tecnológica Federal do Paraná - UTFPR

Ponta Grossa - PR - Brasil

v. 01, n. 02, jul./dez. 2009, p. 08-15

DOI: $10.3895 / \mathrm{S} 2175-08582009000200002$

\section{REVISTA BRASILEIRA DE QUALIDADE DE VIDA}

\title{
Motivação e trabalho: análise do modelo de qualidade de vida no trabalho de Hackman e Oldham
}

\section{Motivation and work: analysis of Hackman and Oldham's quality of work life model}

\author{
Bruno Pedroso \\ Universidade Tecnológica Federal do Paraná - UTFPR - Ponta Grossa - Brasil \\ brunops3@brturbo.com.br \\ Luiz Alberto Pilatti \\ Universidade Tecnológica Federal do Paraná - UTFPR - Ponta Grossa - Brasil \\ lapilatti@utfpr.edu.br
}

\begin{abstract}
Resumo
A avaliação da qualidade de vida no trabalho por meio de métodos quantitativos tem se intensificado na contemporaneidade. Ao contrário do que pode parecer, tal prática teve início na década de 70, com Hackman e Oldham. O presente trabalho objetiva construir uma crítica ao modelo de qualidade de vida no trabalho de Hackman e Oldham. Para mensurar a qualidade de vida no trabalho, os referidos autores criaram um escore denominado Potencial Motivador do Trabalho. Os indicadores que compõem o Potencial Motivador do Trabalho são ramificações de a satisfação oriunda da ambiente laboral. Aduz-se que Hackman e Oldham foram pioneiros na quantificação de instrumentos de avaliação da qualidade de vida no trabalho, mas, não se preocupam em estudar o ambiente laboral em si, levando em conta somente a abordagem comportamental dos trabalhadores. Ainda que se trate de um aspecto importante no ambiente laboral, a qualidade de vida no trabalho transcende a satisfação do indivíduo.
\end{abstract}

Palavras-chave: qualidade de vida no trabalho, instrumento de avaliação, modelo de Hackman e Oldham.

\begin{abstract}
The evaluation of quality of work life through quantitative methods has become more intense recently. Opposite to what it may seem, such practice was launched in the seventieth decade with Hackman and Oldham. The current study aims to build a criticism to Hackman and Oldham's model of quality of work life. In order to measure quality of work life, the aforementioned authors have created a score named Motivating Potential Score. The indicators that compose the Motivating Potential Score are ramifications of satisfaction at the work environment. It is assumed that Hackman and Oldham have been the pioneers in the quantification of the evaluation instruments of quality of work life, but have not been concerned with studying the labor environment itself, taking only the behavioral approach of the workers into account. Although it is an important aspect at the working environment, quality of work life transcends the individual's satisfaction.
\end{abstract}

Keywords: quality of work life, instrument of evaluation, model of Hackman and Oldham. 


\section{Introdução}

A preocupação com a qualidade de vida no ambiente laboral tem sua progênie na Revolução Industrial. Reivindicações originadas de trabalhadores crescentemente organizados, no curso de uma história que nasceu nas "Usinas de Satã", fez com que o trabalho se tornasse mais humanizado ou, principalmente nas fases iniciais, menos desumanizado. A transmutação ocorreu de forma lenta, forjada por pequenas conquistas advindas de difíceis entraves, quase sempre acompanhado de um aparato legal.

O trabalho ocupa uma parcela significativa da vida das pessoas. Fato esse que justifica as intervenções na vida pessoal do trabalhador. Ainda que permeados por variáveis muito semelhantes e grande inter-relação, os conceitos de qualidade de vida e qualidade de vida no trabalho apresentam uma distinção que vem se acentuando com a vida societária que ganhou muito em complexidade.

A constatação de que as vivências no ambiente laboral têm influencia direta e significativa na qualidade de vida do trabalhador conduz ao questionamento se existe um índice mensurável sobre a influência do trabalho na qualidade de vida.

Na tentativa de mensurar o nível de motivação gerado pelo trabalho, Hackman e Oldham (1974) propõem um escore denominado "Potencial Motivador do Trabalho". O presente estudo atém-se em analisar o instrumento quantitativo de avaliação da qualidade de vida no trabalho de Hackman e Oldham.

\section{O modelo de qualidade de vida no trabalho de Hackman e Oldham}

O modelo de qualidade de vida no trabalho de Hackman e Oldham teve a sua progênie associada ao modelo teórico de Hackman e Lawler, publicado em 1971. A reestruturação do modelo teórico predecessor, acrescida da operacionalização dos indicadores propostos neste modelo, resultou no instrumento de avaliação da qualidade de vida no trabalho de Hackman e Oldham, publicado na forma de um relatório técnico em 1974, e, também, na forma de artigo científico em 1975.

A década de 60 foi marcada por significativos avanços no contexto do trabalho. Fatos como as manifestações civis clamando por igualdade social e a inserção da mulher no mercado de trabalho, desenharam um cenário de reestruturação do labor. Após vivenciar um afluente período de expansão econômica, tal contexto se reverte nos Estados Unidos. O cenário que se desenhava instigou o desenvolvimento de pesquisas direcionadas à solvência da crise que emergia.

Com base nos estudos de Hackman e Oldham (1974, 1975), Chang Júnior e Albuquerque (2002) e Davis e Newstrom (2004), pode se afirmar que há três fatores que influenciam na motivação no ambiente laboral, denominados Estados Psicológicos Críticos: conhecimento e resultados do seu trabalho; responsabilidade percebida pelos resultados do seu trabalho e; significância percebida do seu trabalho.

Os Estados Psicológicos Críticos são processos individuais que não podem ser influenciados durante o gerenciamento do trabalho, portanto, é preciso determinar propriedades do trabalho que sejam passíveis de avaliação e mudança, e que possuam influência direta nos Estados Psicológicos Críticos. Estes recebem a denominação de Dimensões Essenciais do Trabalho (CHANG JÚNIOR; ALBUQUERQUE, 2002).

Há, também, fatores secundários que influenciam nas dimensões do trabalho e nos resultados, denominados Resultados Pessoais e do Trabalho: motivação interna ao trabalho; satisfação geral com o trabalho; satisfação com a sua produtividade e; absenteísmo e rotatividade. Por fim, existe a Necessidade de Crescimento Individual, que se correlaciona diretamente com as Dimensões Essenciais do Trabalho e os Resultados Pessoais e do Trabalho. Seguindo essa linha de raciocínio, Hackman e Oldham $(1974,1975)$ propõem o seguinte modelo: 
Figura 1: Modelo de QVT de Hackman e Oldham

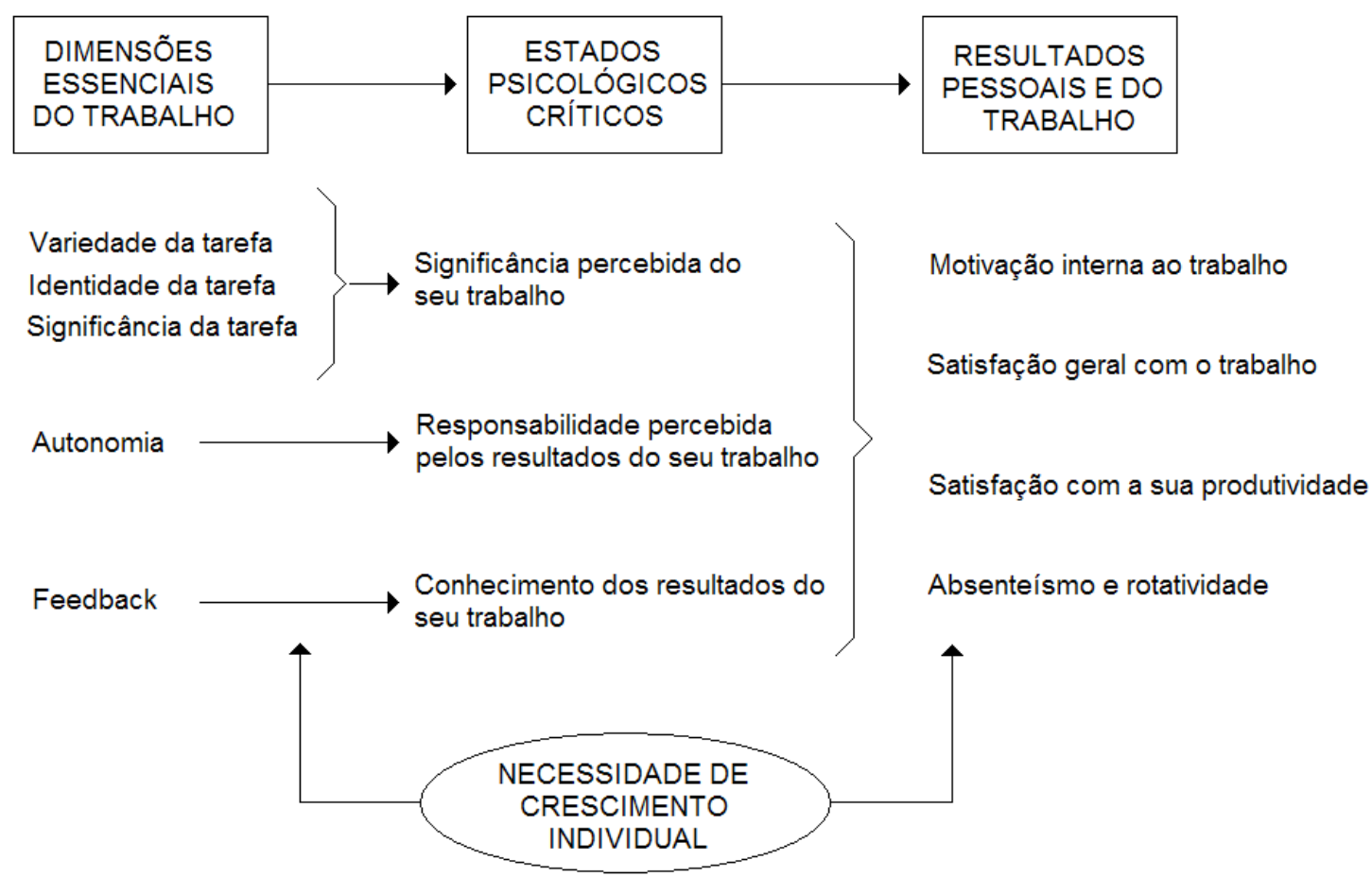

Fonte: Hackman e Oldham (1974), adaptado pelo autor

O instrumento para a determinação do Potencial Motivador do Trabalho avalia as propriedades motivacionais do trabalho, através 15 questões fechadas. As questões possuem enfoque nas cinco Dimensões Essenciais do Trabalho propostas por Hackman e Oldham: Variedade da Tarefa, Identidade da Tarefa, Significância da Tarefa, Autonomia, Feedback.

Dessa forma, o Potencial Motivador do Trabalho "indica o grau até o qual o trabalho é considerado Significativo, fomenta a Responsabilidade e promove o Conhecimento dos Resultados" (DAVIS; NEWSTROM, 2004, p. 154). É um instrumento com questões objetivas, com respostas dispostas em uma escala tipo Likert, de sete elementos. Na maioria dos casos, não demanda mais do que 10 minutos para seu preenchimento.

O cálculo desse escore está calçado na idéia de que "antes que um programa de enriquecimento de trabalho [Qualidade de Vida no Trabalho] tenha início, um empregador precisa estudar tarefas para avaliar quanto elas contêm variedade, identidade, significância, autonomia e feedback" (DAVIS; NEWSTROM, 2004, p. 154). Sob esse enfoque, ressalta-se a importância da existência de uma ferramenta para a determinação, através de uma abordagem quantitativa, do nível de motivação proporcionado pelo trabalho.

\section{Modelo precursor de Hackman e Lawler}

O modelo proposto por Hackman e Oldham (1974) deriva de um estudo anterior realizado por Hackman e Lawler (1971). Neste estudo anterior, foi realizado um levantamento das características presentes no trabalho, de forma a estabelecer condições que motivam os trabalhadores. Os indivíduos tendem a apresentar uma satisfação pessoal significativa quando vivenciam no trabalho elevados índices de Variedade, Autonomia, Identidade da Tarefa e Feedback. Esses quatro fatores foram denominados de Dimensões Essenciais do Trabalho.

De acordo com Hackman e Lawler (1971), as Dimensões Essenciais do Trabalho são variáveis passíveis de mensuração que apresentam as seguintes definições:

- Variedade: o quanto é exigido que os trabalhadores apresentem uma variedade de operações em seu trabalho e/ou utilizem uma variedade de equipamentos e procedimentos em seu trabalho; 
- Autonomia: o quanto os trabalhadores possuem de autoridade para programar as suas atividades, podendo escolher o equipamentos que serão utilizados e decidir os procedimentos que serão empregados;

- Identidade da Tarefa: o quanto os trabalhadores realizam atividades completas em seu trabalho e podem identificar claramente o resultado de seus esforços;

- Feedback: o quanto os trabalhadores recebem informações sobre o seu desempenho no trabalho e/ou o quão corretamente este vem sendo realizado.

Foi convencionado que o nível máximo de motivação é obtido somente quando um trabalho apresenta, simultaneamente, o escore máximo em todas as Dimensões Essenciais do Trabalho. Nesse contexto, para que um trabalho seja motivador, a percepção do trabalhador com relação às cinco Dimensões Essenciais do Trabalho deve ser positiva.

Entretanto, foi constatado a necessidade de determinar se todas as dimensões deveriam apresentar escores elevados para que o trabalhador apresentasse elevada motivação. Nessa perspectiva, o nível de motivação foi correlacionado com as quadro Dimensões Essenciais do Trabalho de três diferentes formas:

a) Somando-se os escores das quatro dimensões;

b) Cada dimensão sendo tratada independentemente;

c) Através do produto dos escores das quatro dimensões.

Os resultados da pesquisa empírica realizada por Hackman e Lawler (1971) demonstraram que o nível de satisfação diminui significativamente quando o escore de uma das dimensões é relativamente baixo em relação às demais dimensões. Fato que não ocorre quando os escores das quatro dimensões são reduzidos na mesma proporção. Assim sendo, as quatro Dimensões Essenciais do Trabalho possuem pesos igualmente distribuídos na determinação da motivação proporcionada pelo trabalho, sendo que a motivação poderia ser calculada através da seguinte fórmula:

\section{Variedade X Autonomia X Identidade da Tarefa X Feedback}

Através da aplicação do instrumento, Hackman e Lawler constataram que, para um trabalho proporcionar elevado nível de motivação, as quatro Dimensões Essenciais do Trabalho devem apresentar escores moderadamente elevados.

Para a determinação do nível motivacional proporcionado pelo trabalho, foi utilizado um questionário composto por 12 questões, seccionado em duas seções. A primeira seção contempla uma avaliação direta do trabalho através de questões fechadas, com respostas baseadas em uma escala de Likert de sete alternativas. Cada questão possui sua própria escala, de forma que o indicador 1 representa o pior resultado, o indicador 4 representa o resultado intermediário, e o indicador 7 representa o melhor resultado. Cada dimensão é contemplada com uma única questão na seção 1 .

A segunda seção faz menção a uma série de aspectos relacionados às quatro Dimensões Essenciais do Trabalho, sendo que o respondente deve assinalar, em uma escala de Likert de sete alternativas, o quanto cada atributo está presente em seu trabalho. O indicador 1 representa "nada ou minimamente", o indicador 4 representa "moderadamente" e o indicador 7 representa "freqüentemente". Os indicadores 1 e 7 sempre representam, respectivamente, o pior e o melhor resultado. Cada dimensão apresenta duas questões na seção 2.

Mesmo que Hackman e Lawler (1971) afirmem que para que o nível de motivação ocasionado pelo trabalho seja alto deve haver equilíbrio entre as quatro Dimensões Essenciais do Trabalho, estes não propõem um escore padronizado para o cálculo do nível de motivação proporcionado pelo trabalho. 


\section{Modelo final de Hackman e Oldham}

Em um estudo subseqüente à Hackman e Lawler (1971), Hackman e Oldham (1974) propuseram uma reformulação do modelo anterior. O novo modelo considera que o trabalho apresenta cinco dimensões essenciais, ao invés de quatro, como proposto no instrumento precedente. A dimensão adicional é chamada de Significância da Tarefa. As Dimensões Essenciais do Trabalho propostas por Hackman e Oldham (1975) são:

- Variedade da Tarefa: o quanto um emprego requer variedade atividades na execução do trabalho, utilização de diferentes habilidades e talentos do trabalhador;

- Identidade da Tarefa: o quanto é exigido que os trabalhadores realizem atividades completas, isto é, atividades que possuem um início em um fim lógico;

- Significância da Tarefa: o quanto o resultado de um emprego impacta na vida ou no trabalho de outras pessoas, tanta na própria organização ou externamente a esta;

- Autonomia: o quanto um trabalho fornece liberdade, independência e privacidade, de forma que o trabalhador possa programar o seu trabalho e determinar os procedimentos que serão empregados para realizá-lo;

- Feedback: grau com o qual a execução das atividades laborais proporcionam ao trabalhador a retroação de informações precisas e claras sobre o seu desempenho no trabalho.

Assim como no modelo de Hackman e Lawler (1971), o modelo proposto por Hackman e Oldham (1974) não trata as Dimensões Essenciais do Trabalho isoladamente e não fundamenta a motivação proporcionada pelo trabalho através da média aritmética das mesmas, mas sim, através do produto das dimensões. Entretanto, o cálculo do nível de motivação do trabalho de ambos os estudo difere-se devido ao fato de Hackman e Oldham (1974) terem atribuído pesos diferenciados às dimensões.

Através da média aritmética entre os escores das dimensões Variedade da Tarefa, Identidade da Tarefa e Significância da Tarefa, seguido de uma multiplicação pelos escores das dimensões Autonomia e Feedback, obtém-se um escore que determina o nível de motivação proporcionado por um trabalho. Este escore é denominado Potencial Motivador do Trabalho.

\section{(Variedade da Tarefa + Identidade da Tarefa + Significância da Tarefa) X Autonomia X Feedback 3}

Nesse novo modelo, o cálculo é realizado por uma medida geométrica, onde, diferentemente do modelo de Hackman e Lawler (1971), as dimensões Variedade da Tarefa, Identidade da Tarefa e Significância da Tarefa, possuem peso menor do que as dimensões Autonomia e Feedback.

Seguindo o modelo de Hackman e Lawler (1971), o questionário para determinação do Potencial Motivador do Trabalho é composto duas seções, sendo este acrescido de três itens que contemplam a nova dimensão, a Significância da Tarefa. Assim, o instrumento proposto por Hackman e Oldham possui 15 questões.

Da mesma forma que a Seção 1 do modelo de Hackman e Lawler (1971), esta primeira seção contempla uma avaliação direta do trabalho através de questões fechadas, com respostas baseadas em uma escala de Likert de sete alternativas. A escala de resposta é diferenciada em todas as questões, sendo que as alternativas fazem menção direta à dimensão do trabalho abordada em cada questão. Em todas as questões, indicador 1 representa o pior resultado, o indicador 4 representa o resultado intermediário, e o indicador 7 representa o melhor resultado. Cada dimensão do trabalho é contemplada com uma questão.

A segunda seção do instrumento é composta por afirmações relacionadas às cinco Dimensões Essenciais do Trabalho, sendo que o respondente deve assinalar, em uma escala de Likert de sete alternativas, qual é o nível de exatidão de cada uma das afirmações, ou seja, o quanto estas estão corretas. O indicador 1 representa "discordância total", o indicador 4 representa "indecisão" e o indicador 7 representa "concordância total".

Ao contrário das Seções 1 e 2 de Hackman e Lawler (1971) e da Seção 1 de Hackman e 
Oldham (1974), os indicadores 1 e 7 nem sempre representam os respectivos pior e melhor resultado. Nessa seção há questões onde a escala de resposta é invertida. Ou seja, o indicador 1 representa a melhor resposta, enquanto o indicador 7 representa a pior resposta. Cada dimensão é representada por dois itens, de forma que um item de cada dimensão está disposto em escala de respostas normal e o outro item está disposto em escala de respostas invertida. É evidentel que o modelo de Hackman e Oldham (1974) teve embasamento no modelo anterior proposto por Hackman e Lawler (1971). As questões pertencentes aos referidos modelos podem ser visualizadas no quadro 1:

Quadro 1: Dimensões do trabalho de Hackman e Lawler e Hackman e Oldham

\begin{tabular}{|c|c|c|}
\hline DIMENSÕES & HACKMAN E LAWLER (1971) & HACKMAN E OLDHAM (1974) \\
\hline \multirow{3}{*}{ Variedade } & $\begin{array}{l}\text { Qual é o nível de variedade presente no } \\
\text { seu trabalho? }\end{array}$ & $\begin{array}{l}\text { Qual é o nível de variedade presente no } \\
\text { seu trabalho? Isso é, até que ponto o } \\
\text { trabalho lhe exige realizar tarefas } \\
\text { diferentes, que requerem habilidades } \\
\text { distintas? }\end{array}$ \\
\hline & $\begin{array}{l}\text { A quantidade de variedade presente em } \\
\text { meu trabalho. }\end{array}$ & $\begin{array}{l}\text { Meu trabalho exige que eu utilize } \\
\text { diversas habilidades complexas ou de } \\
\text { alto-nível. }\end{array}$ \\
\hline & $\begin{array}{l}\text { A oportunidade de realizar uma variedade } \\
\text { de atividades. }\end{array}$ & $\begin{array}{l}\text { O trabalho é bastante extenso e } \\
\text { repetitivo. }\end{array}$ \\
\hline \multirow{3}{*}{ Autonomia } & $\begin{array}{l}\text { Qual é o nível de autonomia existente em } \\
\text { seu trabalho; o quanto você pode decidir } \\
\text { de que forma será realizado o seu } \\
\text { trabalho? }\end{array}$ & $\begin{array}{l}\text { Qual é o nível de autonomia existente } \\
\text { no seu trabalho? Isso é, até que ponto } \\
\text { lhe é permitido decidir a maneira de } \\
\text { realizar suas tarefas? }\end{array}$ \\
\hline & $\begin{array}{l}\text { A liberdade para realizar as atividades da } \\
\text { forma que eu quero. }\end{array}$ & $\begin{array}{l}\text { Em meu trabalho possuo independência } \\
\text { e liberdade para realizá-lo da forma que } \\
\text { eu preferir. }\end{array}$ \\
\hline & $\begin{array}{l}\text { A oportunidade para pensar e agir } \\
\text { independentemente. }\end{array}$ & $\begin{array}{l}\text { Em meu trabalho não tenho nenhuma } \\
\text { oportunidade de tomar iniciativas ou } \\
\text { decisões. }\end{array}$ \\
\hline \multirow[t]{3}{*}{ Identidade } & $\begin{array}{l}\text { O quanto você desenvolve em seu } \\
\text { trabalho, atividades que são iniciadas e } \\
\text { terminadas por você (ao invés de realizar } \\
\text { tarefas que são terminadas por outras } \\
\text { pessoas)? }\end{array}$ & $\begin{array}{l}\text { O quanto você desenvolve em seu } \\
\text { trabalho atividades do inicio ao fim? } \\
\text { Isso é, uma atividade que possui inicio e } \\
\text { fim óbvio? Ou é apenas uma etapa de } \\
\text { uma atividade, finalizada por outras } \\
\text { pessoas ou máquinas? }\end{array}$ \\
\hline & $\begin{array}{l}\text { A oportunidade de terminar as atividades } \\
\text { que eu iniciei. }\end{array}$ & $\begin{array}{l}\text { Em meu trabalho tenho a oportunidade } \\
\text { de terminar as atividades que iniciei. }\end{array}$ \\
\hline & $\begin{array}{l}\text { A oportunidade de realizar atividades do } \\
\text { inicio ao fim, isto é, realizar uma atividade } \\
\text { completa. }\end{array}$ & $\begin{array}{l}\text { Meu trabalho é organizado de forma a } \\
\text { não me possibilitar a realização de } \\
\text { atividades completas, do inicio ao fim. }\end{array}$ \\
\hline \multirow{3}{*}{ Feedback } & $\begin{array}{l}\text { O quanto seu trabalho fornece } \\
\text { informações que permitem avaliar a } \\
\text { qualidade das atividades que você } \\
\text { executa? }\end{array}$ & $\begin{array}{l}\text { O quanto você recebe informações sobre } \\
\text { o seu desempenho no trabalho? Isso é, } \\
\text { você tem conhecimento se o seu } \\
\text { trabalho tem sido bem executado- } \\
\text { através de algum "feedback" que } \\
\text { colegas de trabalho ou supervisores } \\
\text { fornecem? }\end{array}$ \\
\hline & $\begin{array}{l}\text { A oportunidade de descobrir o quão } \\
\text { corretamente eu venho realizando o meu } \\
\text { trabalho. }\end{array}$ & $\begin{array}{l}\text { O simples fato de realizar o trabalho me } \\
\text { proporciona muitas chances para } \\
\text { compreender o quão bem eu venho o } \\
\text { fazendo. }\end{array}$ \\
\hline & $\begin{array}{l}\text { A percepção de que o meu trabalho está } \\
\text { sendo realizado de forma boa ou ruim. }\end{array}$ & $\begin{array}{l}\text { Meu trabalho fornece poucas } \\
\text { informações sobre o desempenho com o } \\
\text { qual eu o realizo. }\end{array}$ \\
\hline
\end{tabular}




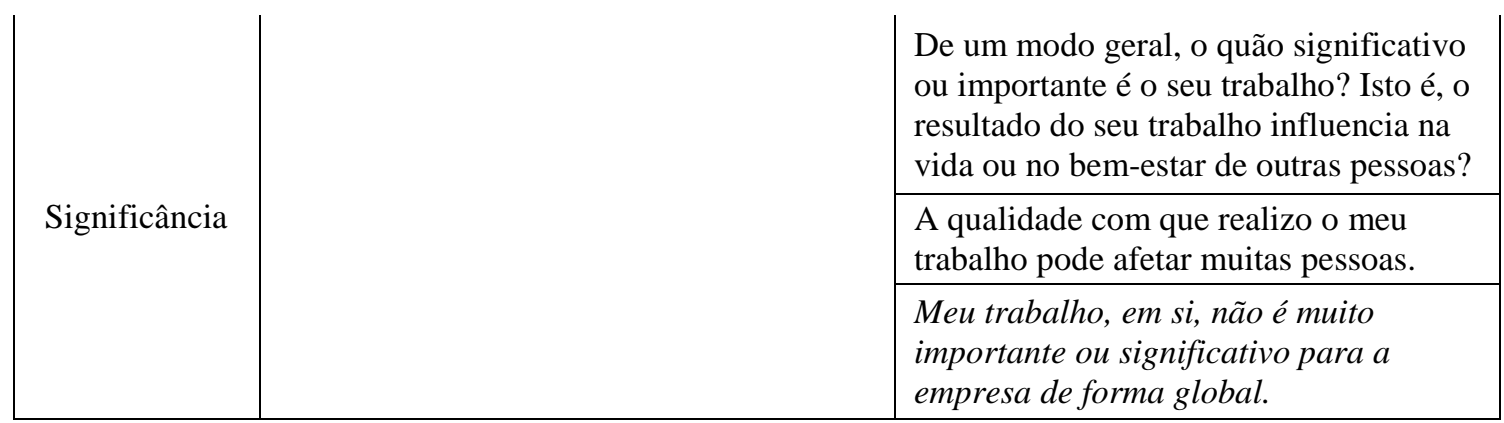

Fonte: Hackman e Lawler (1971); Hackman e Oldham (1974), adaptado pelo autor

As questões presentes na Seção 1 no modelo de Hackman e Lawler (1971) tornam-se mais específicas e diretas no modelo da Hackman e Oldham (1974).

$\mathrm{Na}$ Seção 2, percebe-se que os dois itens relacionados à mesma dimensão, são muito semelhantes. Na tentativa de diferi-los, sem que estes assumam sentidos distintos, Hackman e Oldham (1974) propuseram a inversão da escala de respostas em um dos itens de cada dimensão. Ainda na Seção 2, enquanto Hackman e Lawler (1971) questionam o quanto cada um dos aspectos mencionados está presente no trabalho, Hackman e Oldham (1974) preferem transformar tais aspectos em afirmações, questionando o quanto estas são verdadeiras, do ponto de vista do respondente.

Em se tratando de uma adaptação de um estudo anterior, a principal contribuição de Hackman e Oldham (1974) foi a determinação de parâmetros para se calcular o nível de motivação provinda do trabalho. Nível esse que foi representado pelo escore batizado de Potencial Motivador do Trabalho.

O cálculo dos escores das dimensões do trabalho é realizado através da média aritmética simples entre as três questões que compõem cada dimensão. É preciso inverter as questões cuja escala de respostas é invertida. Quanto ao Potencial Motivador do Trabalho (PMT), este é calculado através da média entre os escores das dimensões Variedade da Tarefa, Identidade da Tarefa e Significância da Tarefa, multiplicado pela escore média da dimensão Autonomia e multiplicado pelo escore da dimensão Feedback.

A pontuação do Potencial Motivador do Trabalho varia entre 1 e 343, sendo que, de acordo com Hackman e Oldham (1974), é utilizado o valor 125 como ponto de referência. Os valores iguais ou superiores a 125 são considerados satisfatórios, enquanto os valores inferiores a 125 são considerados insatisfatórios.

\section{Considerações sobre o modelo da Hackman e Oldham}

O cenário pós-década de 60 dava início a um declínio na economia norte-americana, o que suscitou pesquisadores a inferirem sugestões para se repetir êxito econômico conquistado na década anterior. Na tentativa de corroborar com a situação econômica, que gradativamente se agravava, Hackman e Oldham concentraram seus estudos na construção de um instrumento que mensurasse o índice de motivação oriundo das atividades laborais.

Uma exclusividade do modelo de qualidade de vida no trabalho de Hackman e Oldham é a estruturação da teoria em um instrumento de avaliação quantitativo. Enquanto os modelos demais modelos clássicos de avaliação da qualidade de vida no trabalho são teóricos qualitativos, Hackman e Oldham operacionalizaram os indicadores propostos em seu modelo em uma escala polarizada do tipo Likert. A operacionalização proposta resultou em um instrumento de avaliação que possibilita uma análise quantitativa dos indicadores que o compõem.

Ressalta-se que a elaboração do instrumento quantitativo seguiu uma metodologia criteriosamente elaborada. A utilização de questões com escala de respostas invertida, a transparência das dimensões para os respondentes; a criação de um escore global resultante de todas as dimensões propostas; a atribuição de pesos diferenciados para as dimensões; e a criação de um ponto limítrofe para indicar os limiares de satisfação e insatisfação, constituem aspectos que 
contribuem significativamente para a fidedignidade do instrumento.

Ainda que o modelo em exame apresente pioneirismo no que diz respeito à quantificação da variável qualidade de vida no trabalho, o mesmo apresenta fragilidades. Não houve, por parte de Hackman e Oldham, nenhuma intenção de estudar o ambiente laboral em si, mas sim, apenas a abordagem comportamental do trabalho propriamente dito.

As cinco dimensões essenciais do trabalho são ramificações de um exclusivo aspecto progenitor, que enaltece unicamente uma característica proveniente do ambiente laboral: a satisfação. Mesmo se tratando de um aspecto importante para a avaliação da qualidade de vida no trabalho é pertinente salientar que a multidimensionalidade dessa variável transcende a satisfação do indivíduo.

\section{Referências}

CHANG JÚNIOR, J.; ALBUQUERQUE, L. G. Comprometimento organizacional: uma abordagem holística e simultânea dos determinantes envolvidos no processo. Revista de Administração Mackenzie, São Paulo, v. 3, n. 2, p. 13-38, 2002.

DAVIS, K.; NEWSTRON, J. W. Comportamento humano no trabalho: uma abordagem organizacional - volume 2. 3. ed. São Paulo: Pioneira, 2004. 147 p.

HACKMAN, J. R.; LAWLER, E. E. Employee Reactions to Job Characteristics. Journal of Applied Psychology, v.55, n.3, p. 259-286, 1971.

HACKMAN, J. R.; OLDHAM, G. R. The job diagnostic survey: an instrument for the diagnosis of jobs and the evaluation of job redesign projects. Technical report $n$. 4 , Department of Administrative Sciences of Yale University, may 1974.

HACKMAN, J. R.; OLDHAM, G. R. Development of the job diagnostic survey. Journal of Applied Psychology, v. 60, n. 2, p. 159-70, 1975.

Submetido em 01/08/2009. Aceito para publicação em 20/10/2009. 